\title{
Comprehensive model of safe educational spaces and lifelong learning for educators: regional approach
}

\author{
Elena Murugova ${ }^{1 *}$, Nadezhda Bulankina $^{2}$, Anna Molokova $^{3}$, and Olga Mishutina ${ }^{4}$ \\ ${ }^{1}$ Don State Technical University, Gagarina sq., 1, Rostov-on-Don, 344003, Russia \\ ${ }^{2}$ Novosibirsk Institute of Professional Skills Improvement and Vocational Retraining of Education \\ Workers, Krasniy pr., 2, Novosibirsk, 630007, Russia \\ ${ }^{3}$ Novosibirsk Institute of Professional Skills Improvement and Vocational Retraining of Education \\ Workers, Krasniy pr., 2, Novosibirsk, 630007, Russia \\ ${ }^{4}$ Novosibirsk State Pedagogical University, Viluiskaya str., 28, Novosibirsk, 630126, Russia
}

\begin{abstract}
This article considers approaches to the strategies and tactics of the methodological support for modern teachers' activity in the frameworks of the National Project on Education as seen and presented via innovation humanitarian practices in the current professional community of the Regional Destination (Novosibirsk, Russia). Of particular theoretical and practical significance is the identification of the degree of objectivity and safety of the rationale of Tutoring within a network of consulting centers to provide methodological support for assessing the quality of professional skills and knowledge of educators of the Lifelong Learning stage. The empirical array is the regional centers' activity in the aspect of functional literacy of the participants as the main message of theory, practice and provisions of the comprehensive axiological model of the regional information and education spaces. The conclusion is made on inconsistency of personalized teaching and learning as well as on management of continuing education.
\end{abstract}

\section{Introduction}

Having entered the era more flexibly to individual learners' needs and changing market of digitalization over the last two decades the professional development of a teacher in the frameworks of classical education has changed into the problem of informal continuing education and lifelong learning; this has radically generated significant public and political anxiety, and has led to an intense focus on factors believed to influence the academic achievement of school and university students [1-3].

One of the most important tasks of education is the formation and development of the individual in the conditions necessary for orientation to universal values and national priorities. In this direction, the goals of the state policy are to create an education system that will correspond to the level of developed countries. Lifelong education, recurrent and continuous learning is always an important condition and value orientation for the

\footnotetext{
* Corresponding author: murugovaelena@yandex.ru
} 
professional activity of a teacher. The most flexible educational structure that allows for timely response to the emerging professional and educational needs of the teacher is the system of professional retraining and advanced training. This is primarily due to the ability to respond to changing attitudes in pedagogical concepts and approaches, and is also provided through up-to-date methodological support, the creation of popular pedagogical practices and the development of innovations. Due to the need to constantly maintain the relevance and adequacy of professional and educational needs, the system of retraining and advanced training constantly updates methodological knowledge, explores and applies innovative tools and methods. Thus, with the help of training programs that most effectively reflect professional needs, conditions are created for the teacher's selfrealization, self-development and self-improvement in the main competencies. Systematic training and retraining of teachers consists precisely in the development of pedagogical competence and functional literacy in general, and not in a specific situation at a certain level of education. Then we can say that the system of advanced training is a substructure of continuing education, a necessary part that links together pedagogical education, scientific knowledge and educational practice.

The constant increase in the requirements for high-quality teacher education and the competence of teachers makes it necessary to constantly look for ways and means of developing professionally important teacher competencies. Pedagogical skills, professionalism, pedagogical culture are in this case precisely those components of the teacher's competence that show his qualifications and the pedagogical potential of the individual, while the leading role is given to the competence approach. The task of the system of retraining and advanced training is to form a conscious attitude of the teacher to education throughout life, as well as the need for a recurrent appeal to the development of professionally important knowledge for the teacher, regardless of external objective factors, such as age, lack of sufficient time, territorial restrictions and other obstacles. This is due to the psychological property of the individual that only in constant self-development is it possible to fully realize oneself in a particular professional field. To a large extent, this applies to teaching work, when, by alternating their activities and self-education, the teacher becomes the most effective and maximizes their potential.

Based on the presented and described factors, for the system of professional development as an educational institution, it is important to have forms of improving the professional competence of the teacher and effective technologies that connect the teacher's experience with innovative activities. The desire to stay ahead of the achievements of science and methodology, as well as in terms of professional development and achieving a high level of competence, the application of promising knowledge in practice - all this should form the basis of continuing education.

The recurrent organization of professional development and professional retraining encourages the teacher to use the methodological tools of pedagogical science for the purpose of self-education and encourages research work, which, in turn, activates the creative potential and active exchange of experience, techniques and methods in real time. At the same time, an important characteristic for the educational system of advanced training is the ability to develop, and for the individual in it - the need to learn throughout a life.

One of the most relevant technologies in this case is problem-based learning and interactive learning methods. The combination of creative and problematic technologies helps to create effective solutions in the professional sphere. The product and result of the work are various educational and methodological recommendations, textbooks, didactic materials, plans, programs, scenarios of events, consultations, seminars and round tables. Each lesson in the system of advanced training is conducted with a specific purpose, according to which the content and interactive teaching methods are selected. Classes can 
be held in various forms (lecture, conversation, master-class, seminar), with the use of informal training, as well as with the visiting open lessons and educational organizations. Practical pedagogical activity in the system of professional development of teachers in modern conditions must necessarily be associated with real teaching work. An important component is methodological support and support in the learning process. All this allows teachers studying in the system of advanced training and professional retraining to form their own educational trajectory and get the necessary professionally and personally significant training.

The conceptual vision of the development of continuing education can be presented at the following levels:

1. at the level of professional self-realization, functional and professional literacy, selfimprovement of the individual;

2. at the level of formation of an active and socially significant attitude in society to the constantly changing and developing external environment;

3. at the level of training of qualified and competitive specialists.

During the implementation of continuing education, the professional development system is designed to:

1. Implement lifelong learning.

2. Associate of public and professional interests.

3. Implement the interaction of various social groups with a targeted focus on improving the quality of education.

4. Develop the ability to learn and the ability to accelerate the development of new competencies.

All this allows us to note the relevance of the problems of professional development and retraining of teachers and give them the opportunity to form their own educational trajectory independently and get the professional training required for further professional development. At the same time, it should be noted that the orientation of the system of advanced training and retraining to the modern requirements of society will directly affect the labor market. In modern conditions, the teacher is constantly searching for effective educational technologies and needs continuous professional training with a focus on the ability to further self-improvement.

The problems associated with the professional development (PD) of a teacher have always been in the focus of increased attention from both the society and academic Scholarship due to a radical change in the educational paradigm. More specifically, it addresses practices of teachers' requirements that manifest in multiple ways, and in the aspect of goals, management, programming, planning, teaching and learning, differentiation, from research to professional degrees, modules, work alongside their studies, i.e. pluralism in many areas and aspects. This is considered to become a kind of current ideological trend, philosophy and conceptualization, methodological approach of nowadays to public school system $[4,5]$. And if no innovations, reforms or changes are seen or introduced this phenomenon becomes a sort of drama that takes place $[6,7,8$, 9].The discussions commonly consider the postgraduate additional education as a system that requires efficacy in the use of innovative approaches and models of training proposed by researchers; this also concerns the development of professional competencies, the level of professionalism and communicative skills of a modern teacher. Continuing education and lifelong learning are put forward as a target setting. Within this system the educators have to participate once three years in a professional development program designed to support them in bridging the gap between visionary reforms and classroom practice. Then, teachers are to highlight instructional strategies modeled during the course as supportive together with easy access to teaching resources and increased confidence $[10,11]$. 
An analysis of the thesis papers of current scientific scholarship showed that the recent events of the third millennium with its collisions increasingly affect the problem of relationship between social and human relations in various contexts $[12,13]$ where value aspects of teacher's activity currently find itself in the focus of systemic care at personal/individual level. Implications for future professional development programs are constantly discussed at the universities and in the studies devoted to PD [14]. As the world is in transition, so PD of a teacher is itself taking new forms. This has always been true: researchers note a departure from the classical model of education to the philosophy of a pluralism of ideas, opinions and concepts, alternative pedagogical practices and value orientations, strategies and tactics of human interaction in the polyphony of information and education spaces. Dominant values are understood as generally accepted ideas of people about the goals and devices to achieve them, socially accepted primarily ways of speech behavior.

Problem Statement concerns the fact of PD of a teacher that is in need of innovative changes and transformations. In this regard, it is the clarification of the role and status of Tutoring within regional consulting centers and In-Service educational institutions, what the similarities and differences in their provisions along with the conditions of fruitful collaboration are significant.

It is these ideas that become the basis for moral principles of life, and an individual discussion, currently, in academic Scholarship [15, 16]; the studies are carried out in an applied manner and on the grounds of system of socially and culturally significant values is established in every social system. Actual issues of continuing education, education for life, and the problem of Lifelong learning for the youth and adults are under system and axiological levels. In these articles, the authors see their humanistic mission in motivating them to innovations, changes, and consider the definitions and criteria for evaluating the efficacy of public and municipal mentors and tutors, identification of the motivational factors of their activities within management by goals, of the graphic rating scale, of 'forced' selection, the descriptive method, and the method of questionnaires. The above issues are relevant to the analysis of modern strategies for Russian education and Lifelong Learning of a pedagogue.

The goal of the opus is to present a comprehensive model of dominant values of professional development of a teacher in terms of axiological approach to the formation of safe information and communication spaces and provisions for lifelong learning of a person.

\section{Concept and methodology}

The civilizational development of society shows that the key to a successful educational trajectory and the development of professional literacy depends on the general and pedagogical culture of the individual. The training of a well-rounded teacher also depends on the general culture and the culture of the word. One of the main problems of education for teachers is the process of mastering the modern characteristics of the culture of the individual, which makes it possible to effectively make the concept of lifelong learning. The creation of a comprehensive model, the cultural aspect of which must be taken into account no less than the content and personal meanings, is a necessary condition for the professional growth of teachers. Modern culture includes information competencies, such as the collection, storage, processing, transmission, analysis, and generation of fairly large amounts of information. These processes are especially important and relevant at this stage of the civilizational development of the global society, in which one of the main resources is information for pedagogical work, which often has a long-term result and does not keep up with the development of innovative technologies in its productivity. Nevertheless, the 
effectiveness, quality and effectiveness of the teacher's work has a special impact on the overall human potential of the country. And Russia is no exception. Pedagogical work and its quality are a necessary and integral process of increasing the level of development in all branches of production and other human activities. Therefore, professional development throughout life is always a relevant and promising direction. Pedagogical support and support of the process of professional activity and growth of the teacher should be implemented in the conditions of creative activity, without separation from research practice and practical activity. In our study, we use this approach of improving the professional competence of teachers, which allows us to consider the entire pedagogical process as a set of mechanisms for developing the professional competence of a teacher, which we refer to: the use of remote technologies in advanced training courses, consulting services, active participation in training and seminar sessions and webinars, the development and description of our own research, the generalization and application of advanced pedagogical experience, creative certification, the use of innovative methods, techniques, means of training and technologies in their professional activities.

Intensive changes in society, modernization of all spheres of modern society have significantly actualized the tasks associated with the development of the competencies of teachers of educational organizations that are at the origins of high-quality further education of students. The analysis of the professional needs of teachers allows us to conclude that the professionally significant values of a modern teacher do not correspond to the requirements of educational standards: there is a dominance of socio-economic values over spiritual, moral and universal values; to date, the main value and meaning of the teacher's pedagogical activity remains knowledge, skills and abilities that replace the indicators of the versatile development of the teacher. In addition, the existing social reality requires changes in the content of the value-professional space of the teacher, which creates conditions for the implementation of pedagogical interaction on the basis of formed professionally significant values characteristic of professional pedagogical activity, characterized by value saturation, which determines the formation and transmission of educational and life values.

At the scientific and theoretical level, the relevance of the problem is determined, on the one hand, by identifying potential opportunities for acquiring the values of teachers necessary for the implementation of professional functions in the course of professional development, and, on the other, by setting goals and objectives that involve improving the quality of postgraduate education.

The scientific and methodological level of relevance of research work is determined by the definition of a complex of organizational and pedagogical conditions for overcoming obstacles in professional activity and acquiring skills of reflection of professionally significant values.

The system of professional development is designed to eliminate certain difficulties that hinder the development of professionally significant values that make up a positive beginning for improving the professional competence of a teacher. The educational process, built on the inclusion of the teacher in active activities to achieve professionally significant values, differs from the traditional one, aimed at overcoming professional difficulties, in that it acquires an emotional positive impulse of striving for the ideal and becomes effective.

The professional development programs developed on the traditional principles of training, focused on the use of reproductive methods of information transmission, only to some extent meet the needs of teachers related to the awareness of the values and meanings of modern education [17]. The process of professional development, built without taking into account the fact that the professional path of a teacher is not only an everyday educational activity, but also the value sense invested in it, does not give the results 
expected by the teacher. Additional education based on a practice-oriented approach use of laboratories, computer classes, quantorium, and classrooms equipped with interactive equipment allows us to solve this problem. In practical activities aimed at rethinking professional failures and mistakes, the teacher's attitude to everything that happens in the educational process changes. Creative and reflexive activity becomes an internal conscious work of the teacher's personality and a professional value [18]. The internship, organized taking into account the personal interests of the teacher, opens up opportunities for finding elements that form the individual style of the teacher's skill, revealing and developing his professionally significant values.

Concerning the problem of comprehensive model designing of safe educational spaces and lifelong learning for educators we based on the aspects, which form prerequisites for creating a safe space, presented by Veronika Kisfalvi and David Oliver [19] and specified in the Table 1.

Table 1. Prerequisites for a safe space and approaches to achieving it.

\begin{tabular}{|c|c|c|}
\hline $\begin{array}{l}\text { Prerequisites for creating a safe } \\
\text { space }\end{array}$ & $\begin{array}{l}\text { Approaches to creating and } \\
\text { maintaining a safe space }\end{array}$ & Examples \\
\hline Physical aspects & $\begin{array}{l}\text { Create a strong container } \\
\text { early on }\end{array}$ & $\begin{array}{l}\text { Use movable fumiture; sit in a } \\
\text { circle }\end{array}$ \\
\hline Time and timing & $\begin{array}{l}\text { Create a strong container } \\
\text { early on }\end{array}$ & $\begin{array}{l}\text { Warm up ice breakers; provide } \\
\text { transparent direction of } \\
\text { classroom processes }\end{array}$ \\
\hline $\begin{array}{l}\text { Suspension of judgment/ no } \\
\text { censorship }\end{array}$ & Establish ground rules & $\begin{array}{l}\text { No put-downs; right to pass } \\
\text { one's tum }\end{array}$ \\
\hline Mutual trust and respect & Teach by example & $\begin{array}{l}\text { "Holding"; model caring body } \\
\text { language }\end{array}$ \\
\hline Qualities of listening & Bear witness & $\begin{array}{l}\text { Use "third ear" to attend to } \\
\text { sub-texts and preconscious } \\
\text { materia }\end{array}$ \\
\hline Reflexivity & Model a reflexive attitude & $\begin{array}{l}\text { Share own self-questioning; } \\
\text { sit in on colleague's classes }\end{array}$ \\
\hline
\end{tabular}

The empirical array is threefold for the study of a) the passport texts of official concepts of Russian education development projects reflected in a number of approved state documents (Law on "Education", 2012, National Project "Education", 2019) that specifically address practices of teachers' requirements in the spaces of individual learners' needs and changing market of digitalization; b) current academic Scholarship on PD that reflect on the development of system models of Tutorials in the frameworks of both motivational and knowledge content support for mentors and tutors of the regional consulting centers which are in search of indicators of efficacy of the national public school system; and c) the authors' projects on "Methodological support for educators: the aspect of recurrent education" that vary in their modes of delivery, providing in digital supported teaching and learning environments as form as options for part-time or full-time study, aligning work and study in of blended learning. This conceptual framework of the three main constructs - creating, implementing and evaluating effective professional development efforts to answer the three major questions of who, what and how within a wider context based on the Comprehensive Model of CSD on the underlying mechanisms that facilitate changes lifelong learning of an individual [20, 21].

Research methods - interpretation, modeling, generalization, questionnaires and interviews, content analysis of the products of oral and written statements and their statistical processing. 


\section{Research results and discussion}

In this section, we review the basics of CSD of the educationists who are considered "vehicles of power" and must provide circumstances for students to accomplish empowerment. It is only possible when they are ready to take a critical stance to their activities. The results of Scientific exposition are based on thorough review of current scientific Scholarship and innovation practices which reflect on the development of system models of Tutorials in the frameworks of both motivational and knowledge content support for mentors and tutors of the regional consulting centers which are in search of indicators of efficacy of the national public school system based on assessment.

At the first stage, the aim was to determine the above identified aspects related to the change of the educational paradigm as a whole, with new educational concepts and promising approaches to the management of information and educational flows in pedagogical science and practice that allowed us to formulate the main goal and objectives in terms of adjusting the Comprehensive model of CSD of the individual at the regional level. Thorough review shows that this model finds support in the studies of other Russian researchers.

The micro-study is organized as continuation of the scientific pedagogical research work of the staff of the In-Service Institute (Novosibirsk Destination) coupled with previous work on culture-identity of the teacher. In the period from 2012 to the present, a basic study was conducted in twenty general education organizations of the region (more than 1200 educators) and municipal consulting centers, the purpose of which is to adjust the complex model of CSD of the individual in the new conditions of the organization of the regional system of additional professional education of teachers. Teaching quality observations of about 1000 educators (primary, middle and high school teachers) with three years' experience in the spaces of 43 consulting centers state no evidence of less competence for teachers with over 3 years' experience, some evidence of decline in teaching quality in educators with over ten years' experience, and the importance of system support and professional learning a priority for all teachers, not just beginners.

At the second stage based on the importance of these problems is to focus on the development of their holistic vision - philosophical understanding and pedagogical solutions to improve its qualitative characteristics - the ability of students to reflect, selectivity, responsibility for words and deeds, subjectivity, meaning formation, creativity, recognition of the value of other people, etc. The main concept concerns the idea of becoming a must for educators to study the problems of the quality of education in a complex, emphasizing its economic component and largely due to the competitiveness of the country "in the conditions of the formation of a "knowledge society" and the growth of "intellectual potential" and considering that "in the national context, the quality of education is its compliance with the modern life needs of the country's development; in the pedagogical context, it is the creation of conditions for the comprehensive development of the students "personality".

At the third stage professional development spaces are often considered as a broad variety of facilitated learning opportunities, ranging from single-off workshops and consultations to comprehensive curricula and communities of practice where all actions and activities focused on education, training and development opportunities for professionals with the ultimate goal of improving children's developmental or educational out-comes. The project database covers a number of management measures proposed by researchers and educators of the In-Service Institute, the authors of this article, i.e. three problem sessions, two initial and one final dedicated to the best pedagogical practices; routemapping, e-learning resources on Pisa exams, and planning of educators' sittings CLIL (Content and Language Integrated Learning), STEM (Science, Technology, Engineering, 
Maths) technologies; topicality issues seminars, co-working, conferences, and classes observation database; formative assessment programs on teachers' knowledge about supporting students' reflection, feedback on reflection involving an expertise-based formative assessment of functional literacy, in which teachers received training and feedback from a certified trainer and manager of consulting centers, both in individual and group sessions.

\section{Conclusion}

The joint project made it possible to adjust Comprehensive Model at the final stage of the study, as well as to outline the prospects for the teachers' participation in the events based on integration processes. Export of innovative practice into professional spaces is not as easy as it seems to be at the moment because of deficiencies of management methodology of the consulting centers. In this paper we addressed the question of how the Model measurements can reflect their environment in the Centers signal, i.e. in their activity. Current analyses are sensitive only to very small or extremely large eccentricity to receive feedback which has a frequency shift from expectations. In particular, we note that the evidence of the efficacy of the proposed Model is real events in the region, where this annual work that has been carried out on the dissemination of innovations partly solve the problem of cultural interaction in some of the municipal public schools. Locality of largescale events, the rapport of the teachers who are ready to humanize interaction in terms of personified teaching and learning, are important criteria of the activity, because it proves the concept of all learning as a "social accomplishment" (according to Vygotsky's theory) of spending time together in promoting relational development where a good rapport between the teacher and the students is a fundamental need in any modern, student-centered approach to education.

The identified and justified theoretical and methodological grounds for creating a pedagogical model for the development of professionally significant values of a teacher in the system of professional development at the general scientific, specific scientific and methodological and technological levels of methodology allowed for the integration of methodological approaches and basic principles that ensured its methodological multilevelness and hierarchical nature due to structural interrelation and conceptual unity.

The fundamental ideas of the pedagogical model, certain and justified factors that influence the development of professionally significant values of the teacher in the system of professional development, create a scientific and theoretical basis for the development of concepts and directions of professional development of teachers.

The semantic content of the developed conceptual model of the development of professionally significant values of a teacher in the system of professional development creates a scientific basis for the use of integrated material in the educational process, which is didactically prepared by the teacher, taking into account its value-oriented, motivationalsemantic, reflexive-correctional orientation, including the integration of structural components of professionally significant values of a teacher.

Modern educational approaches, concepts and technologies should take into account the change of educational paradigms and its shift in the field of professional training and methodological support of teachers towards a more flexible and adaptive strategy. Our research proves that it is the uniqueness of the individual and the individualization of methodological support that are at the center of teacher training and the development of advanced pedagogical experience. It is important to note that the development of experience is impossible just from the side of the content component. The second rather important component of teachers' professional growth and development is the awareness and internalization of the meanings and values that a teacher needs for personal and 
professional growth. In the training process of the teachers, taking into account the individual characteristics, abilities and capabilities of students, focusing on modern achievements of pedagogical science and practice - all these aspects should be designed to encourage teachers to master advanced technologies and implement the most optimal and effective methodological techniques in their own professional activities. Such an integrated educational model, which takes into account various regional problems, priorities, educational tactics and target results of teacher training will lead to their successful functioning and partially provide a higher level of functional literacy.

Features of cognitive personality types of students is also one of the aspects of learners' interest in the process of acquiring personal meanings associated with professional growth and development. Taking into account such cognitive personality types according to their classification by type of thinking for introverts, extroverts, kinesthetic, visualizers, controllers, perceivers, as well as the influence of age-related personality characteristics on the learning process also affects the success of mastering innovative educational methods and their further application be the learners of the training courses. In our research, we have repeatedly received confirmation that the majority of trained teachers show a willingness to reflect and analyze actively the shortcomings of their professional activities, subjective and objective problems and tasks to solve them, show responsibility for the results of their own growth and development in the professional field, and they also prefer lifelong learning as an integrative way to improve their skills.

When conducting consultations and training sessions, it is necessary to receive feedback and offer flexible solutions to current professional tasks of teachers and thereby provide the necessary methodological and pedagogical support. This approach allows us to organize independent research effectively, use open discussions and individual projects in accordance with the cognitive-psychological, content and needs characteristics, which can be most successfully implemented in an integrated educational process in the form of lifelong learning.

One of the main components of improving pedagogical competence is consulting support and support of methodological work of teachers of various educational organizations. In our study, we tracked, analyzed and described such components of the methodological work of an educational organization as open classes, contests of methodological manuals, analysis and implementation of interdisciplinary connections in didactic materials and approaches to learning, and others. The study used training courses of methodological training based on the organization of conferences, competitions, analysis of teacher surveys, comparison and comparison of innovative pedagogical experience, participation in problem seminars. It should be taken into account that lifelong learning should represent modern innovative pedagogical technologies and approaches, as society and knowledge are constantly developing and gaining growth in terms of solving current problems with the help of new and more effective methods. This process also affects professional teaching activities.

The purpose of applying a comprehensive model of safe educational spaces is to create conditions for consciousness of cultural, value and professional growth of pedagogical competence. The aspects and problems considered in our study in the field of creative development of teachers indicate that in the process of professional growth and increasing competence, the teacher implements the processes of self-development and realization of creative abilities, as well as awareness of the teacher's status in society and in the professional sphere of activity. At the same time, it should be noted that the content aspect is important as well as the ability and willingness to learn continuously, make realized choices, and possess the skills to find and select the right solutions. In modern conditions, the achievement of a high level of creativity of a teacher cannot be achieved completely, relying only on traditional systems of professional development, since intensive creative 
activity requires a willingness to master new knowledge constantly using active, interactive and problem-based methods, understanding their essence, and developing the ability to use them in self-development, self-education and the ability to effectively apply them in creative pedagogical work. In the presented educational model of safe educational spaces, the content and technologies of teaching should be aimed at developing the creativity of teachers in their approach to their practical and research activities. The prospects of this approach and the effectiveness of the proposed model in the continuing education of teachers were proved by this study.

\section{References}

1. M.A. Dremina, N.N. Davydova, V.A. Kopnov, Multilingual Academic Journal of Education and Social Sciences, 4(1), 30-56 (2016). DOI: https://doi.org/10.6007/MAJESS/v4-i1/2046

2. A.E. Garzón, T.S. Martínez, J.L.O. Martín, J.A. Marín, G.G. García, Sustainability, 12, 2852 (2020) DOI:10.3390/su12072852

3. Tatyana Lopatukhina, et al., INTED2020 Proceedings, 7413-7419, (2020) DOI: 10.21125/inted.2020.1984

4. B.R. Romijn, P.L. Slot, P.P.M. Leseman, Teaching and Teacher Education, 98 (2021) 103236 - DOI: https://doi.org/10.1016/j.tate.2020.103236.

5. N. Volles, SSRN Electronic Journal, 1-21 (2014) URL.: http://www.tandfonline.com/doi/abs/10.1080/03075079.2014.927852, DOI: $10.2139 /$ ssrn. 2511176

6. T. Dmitrieva, E. German, T. Khvatova, SHS Web of Conferences 44, 00029, (2018) DOI: https://doi.org/10.1051/shsconf/20184400029

7. S. Dudko, SHS Web of Conferences 29, 01019, (2016) DOI: https://doi.org/10.1051/shsconf/20162901019

8. Ekaterina Egorova, et al., EDULEARN20 Proceedings, 899-904 (2020) DOI: 10.21125/edulearn.2020.0315

9. Sh. Pozilova, N. Rasulova, Sh. Khalilova, N. Aliyeva, M. Rasulova, Journal of Critical Reviews, 7(7), 379-383 (2020) DOI: http://dx.doi.org/10.31838/jcr.07.07.63

10. R.C. Ramola, International Journal of Computer Engineering in Research Trends, 8,2 (2021) DOI: https://doi.org/10.22362/ijcert/2021/v8/i2/v8i203

11. E. Cendon, Journal new approaches in educational research, 2(7), 81-87 (2018) DOI: 10.7821/naer.2018.7.320

12. B.S. Haug, S.M. Mork, Teaching and Teacher Education, 100, 103286 (2021) DOI: https://doi.org/10.1016/j.tate.2021.103286

13. D. Hotaman, Journal of Curriculum and Teaching 9(3):33, (2020) DOI: $10.5430 /$ jct.v9n3p33

14. P.A. García-Tudela, M.P. Prendes-Espinosa, I.M. Solano-Fernández, Journal of new approaches in educational research, 2(9), 245-258 (2020) DOI: https://doi.org/10.7821/naer.2020.7.562

15. J. Field, Second International Handbook of Lifelong Learning, 887-897 (2012) DOI: 10.1007/978-94-007-2380-3_54

16. L.J. Graham, S.L.J. White, K. Cologon, R.C. Pianta, Teaching and Teacher Education, 96, 103190 (2020) DOI: https://doi.org/10.1016/j.tate. 2020.103190 
17. N.E. Bulankina, N.N.Malahova, E.V. Egorova, A.S. Seredintseva, V.A. Tsybanjeva, E3S Web of Conferences, 210, 22017 (2020) doi: 10.1051/e3sconf/202021022017

18. T.B. Mikheeva, M. Elagina, E3S Web of Conferences 210, 18029 (2020) https://doi.org/10.1051/e3sconf/202021018029,

https://www.scopus.com/record/display.uri?eid=2-s2.085098496289 \& origin $=$ resultslist

19. V. Kisfalvi, D. Oliver, Journal of Management Education, 39(6), 1-28 (2015) doi:10.1177/1052562915574724

20. T. Lopatukhina, E. Egorova, V. Sizyakina, ICERI2020 Proceedings, 2287-2291 (2020) doi: 10.21125/iceri.2020.0548 (2020).

21. T. Mikheeva, E. Murugova, Y. Morozova, V. Demchenko, INTED2020 Proceedings 14th International Technology, Education and Development Conference 1211-1215 (2020) doi: $10.21125 /$ inted.2020.0417 